\title{
Hubungan Lama Kerja Perawat Dengan Kepatuhan Pengisian Surgical Safety Checklist Di Instalasi Bedah Sentral
}

\author{
Maria Karolina Selano', Yohanes Hendy Kurniawan², Priyo Sambodo 3 \\ ${ }^{1}$ Sekolah Tinggi Ilmu Kesehatan Elisabeth Semarang \\ 2,3 Rumah Sakit St. Elisabeth Semarang
}

\section{Article Info}

\section{Article History:}

Accepted May 3rd 2019

\section{Key words:}

Length of work; Obedience;

Surgical safety checklist

\begin{abstract}
The use of the Surgical Safety Checklist reduces mortality and surgical complication. Nurse obedience in documenting the surgical safety checklist is still low. It is showed that there is a lack of nurses awareness about the importance of surgical safety checklist in an operation. This research aims to know about the relationship between the years of service of the nurse and compliance with filling surgical safety checklist at Central Operating Theatre. Design of this study uses cross-sectional approach. Sampling technique uses total sampling technique, samples taken for study as many as 23 respondents who met the inclusion and exclusion criteria. The data are described in table form and a Fisher test was conducted with spss 21. The highest work period are they who have light of work $\geq 3$ years as many as 15 respondent $(65,2 \%)$ and respondents who have length of work $<3$ years as many as 8 respondent (34,8\%), for nurses obedience 18 respondents $(78,3 \%)$ who did not complete the surgical safety checklist while 5 respondents $(21,7 \%)$ complete the surgical safety checklist correctly. Fisher statistic test obtained p-value data is $0,586>0,05$. There is no relationship between the years of service of the nurse and compliance with filling surgical safety checklist at Central Operating Theatre
\end{abstract}

\section{PENDAHULUAN}

Rumah sakit adalah institusi pelayanan kesehatan yang menyelenggarakan pelayanan kesehatan perorangan secara paripurna yang menyediakan rawat inap, rawat jalan dan gawat darurat. Salah satu fasilitas pelayanan di rumah sakit adalah pelayanan pembedahan/operasi. Rumah sakit mengutamakan keselamatan pasien untuk meningkatkan mutu pelayanannya dan mendapatkan kepercayaan serta kepuasan masyarakat terkait dengan pelayanan yang telah diberikan. Pemerintah mewajibkan program keselamatan pasien di setiap rumah sakit dan akan dievaluasi melalui akreditasi oleh Komisi Akreditasi Rumah Sakit ( T Bramantoro, 2017)

Keselamatan pasien dan kualitas pelayanan pasien adalah hal yang sangat penting dari penyampaian layanan kesehatan. Untuk setiap pasien, anggota keluarga dan profesional kesehatan, keselamatan sangat penting untuk penegakkan diagnosa, tindakan kesehatan dan perawatan. Dokter,

Corresponding author:

Maria Karolina Selano

mariaselano100284@gmail.com

Jurnal Kepemimpinan dan Manajemen Keperawatan, Vol 2 No 1, May 2019

DOI: http://dx.doi.org/10.32584/jkmk.v2i1.267

e-ISSN 2621-5047 
perawat dan semua orang yang bekerja di sistem kesehatan berkomitmen untuk merawat dan membantu pasien dan memiliki keunggulan dalam penyedia layanan kesehatan untuk semua orang yang membutuhkan. Namun sistem kesehatan diseluruh dunia, menghadapi tantangan dalam menangani praktik yang tidak aman, profesional layanan kesehatan yang tidak kompeten, tata pemerintahan yang buruk dalam pemberian layanan kesehatan, kesalahan dalam diagnosis dan perawatan dan ketidakpatuhan terhadap standar keselamatan pasien (D, Madden 2018)

Keselamatan pasien rumah sakit adalah suatu sistem dimana rumah sakit membuat asuhan pasien lebih aman yang meliputi asesmen risiko, identifikasi dan pengelolaan hal yang berhubungan dengan risiko pasien, pelaporan dan analisis insiden, kemampuan belajar dari insiden dan tindak lanjutnya serta implementasi solusi untuk meminimalkan timbulnya risiko dan mencegah terjadinya cedera yang disebabkan oleh kesalahan akibat melaksanakan suatu tindakan atau tidak mengambil tindakan yang seharusnya diambil (Biyang, fanny. 2008) Permasalahan patient safety terus diteliti dan dikembangkan oleh berbagai pihak penyedia layanan kesehatan. Berdasarkan Hasil penelitian Diah Pratiwi tentang Faktor- faktor yang berhubungan dengan penerapan patient safety pada perawat menyatakan ada hubungan antara pendidikan, pelatihan, pengetahuan dan motivasi dengan penerapan patient safety di instalasi rawat inap Rumah Sakit Umum Pancaran Kasih GMIM Manado (Diah Pratiwi Renoningsih, n.d. 2016)

Keselamatan pasien menjadi pusat perhatian dari Organisasi Kesehatan Dunia (WHO) termasuk indonesia, sejak tahun 2002 WHO melakukan kampanye mengenai keselamatan pasien dan pada tahun 2008 mencanangkan Safe Surgery Save Lives untuk meningkatkan keselamatan pada pelayanan bedah di dunia bagi seluruh negara negara anggotanya (Biyang, fanny,
2008) Menurut penelitian Karlina tentang evaluasi kepatuhan tim bedah dalam penerapan surgical safety cheklist WHO pada operasi bedah mayor di instalasi bedah sentral PKU Muhammadiyah Bantul menyatakan pengisian surgical safety checklist baik sign in, time out, maupun sign out di Instalasi Bedah Sentral RS PKU Muhammadiyah Bantul termasuk dalam kriteria kurang patuh (Karlina, 2018)

Menurut penelitian Efa Trisna tentang hubungan persepsi tim bedah dengan kepatuhan penerapan Surgical Patient Safety pada pasien operasi bedah rumah sakit umum daerah Mayjend HM. Ryucudu didapatkan hasil ada hubungan bermakna antara persepsi tim bedah dengan kepatuhan penerapan Surgical Patient Safety (Trisna, 2016) Sedangkan Penelitian menurut Apriana Rista tentang hubungan beban kerja dengan kepatuhan pengisian surgical patient safety cheklist pada perawat di ruang Instalasi Bedah Sentral Rumah Sakit St. Elisabeth Semarang menyatakan bahwa ada hubungan antara beban kerja dengan kepatuhan pengisian surgical safety checklist pada perawat di Instalasi Bedah Sentral Rumah Sakit St. Elisabeth Semarang (Apriana, astuti, \& Dedy, 2018)

Kamar bedah Rumah Sakit Swasta Semarang mempunyai 32 perawat dengan lama kerja perawat kurang dari 3 tahun sebanyak 8 perawat (21\%) dan lama kerja lebih dari 3 tahun sebanyak 24 perawat (79\%). Lama kerja adalah suatu kurun waktu atau lamanya tenaga kerja itu bekerja disuatu tempat. Instalasi Bedah Sentral Rumah Swasta Semarang mempunyai Standar Prosedur Operasional (SPO) mengenai surgical safety checklist yang terdiri dari tiga fase yaitu verifikasi pertama pada pasien yang akan dilakukan tindakan (fase sign in), verifikasi sebelum pasien dilakukan insisi pembedahan (fase time out), verifikasi tahap akhir sebelum operasi selesai dan pasien meninggalkan ruang operasi

( fase sign out). Prosedur ini selalu dilakukan pada setiap 
tindakan pembedahan. Perawat sirkuler dikamar bedah bertugas melaksanakan setiap fase tersebut dan mendokumentasikannya dalam lembar surgical safety checklist yang telah tersedia.

Hasil observasi di Instalasi Bedah Sentral Rumah Sakit Swasta Semarang pada tanggal 12 - 29 september 2018 terdapat 41 tindakan operasi. Kelengkapan dokumentasi pada lembar surgical safety checklist hanya 5 dokumen (10\%) yang lengkap dan 36 dokumen (90\%) tidak lengkap. Dokumen yang tidak lengkap yaitu pada fase time out dan fase sign out. Pada fase time out yang sering terjadi adalah tidak ada pengisian pemberian profilaksis antibiotik atau salah penulisan dalam pengisiannya, tidak mengisi perkiraan lama operasi dan perkiraan jumlah kehilangan darah selama operasi sedangkan pada fase sign out tidak mengisi konfirmasi nama tindakan operasi serta pengisian kelengkapan jumlah instrumen, kasa dan jarum operasi.

Berdasarkan fenomena tersebut peneliti tertarik untuk melakukan penelitian tentang hubungan lama kerja perawat dengan kepatuhan pengisian surgical safety checklist di Instalasai Bedah Sentral Rumah Swasta Semarang.

\section{METODE}

Penelitian ini menggunakan metode kuantitatif dengan desain penelitian deskriptif menggunakan pendekatan cross sectional untuk mempelajari hubungan lama kerja dengan kepatuhan pengisian surgical safety checklist di Instalasi Bedah Sentral Rumah Sakit Swasta di Semarang. Cara pengumpulan data dengan observasi, data yang digunakan adalah data sekunder berupa lembar surgical safety checklist pasien yang dilakukan tindakan operasi.

Populasi dalam penelitian ini adalah seluruh perawat ruang Instalasi Bedah Sentral di Rumah Sakit Swasta Semarang yang berjumlah 32 perawat. Teknik pengambilan sampel menggunakan tehnik total sampling dengan kriteria sampel adalah perawat sirkuler di Instalasi Bedah Sentral Rumah Sakit Swasta Semarang yang berjumlah 23 responden. Penelitian ini dilaksanakan pada tanggal 12 - 26 Januari 2019. Analisa data yang digunakan adalah analisa univariat untuk mendeskripsikan lama kerja dan kepatuhan pengisian surgical safety checklist dan analisa bivariat untuk menganalisa hubungan antara lama kerja dengan kepatuhan pengisian surgical safety checklist dengan menggunakan SPSS 21. Uji yang digunakan yaitu uji fisher.

Etika penelitian yang dilakukan yaitu peneliti menjaga kerahasiaan hasil penelitian baik informasi maupun masalah lain yang menyangkut privasi responden serta peneliti memberikan jaminan kepada responden dalam penelitian dengan tidak mencantumkan nama responden pada lembar observasi tetapi memberikan kode atau inisial. Setelah data diperoleh, peneliti melakukan pengolahan data dengan menggunakan beberapa tahap. Tahap pertama dari penelitian ini adalah editing untuk memeriksa kembali kebenaran data yang diperoleh atau dikumpulkan dengan melakukan pengecekkan kelengkapan lembar surgical safety checklist dan lembar observasi.

Tahap kedua dari proses pengolahan data yaitu coding. Kode yang digunakan pada variabel lama kerja yaitu kode $1:<3$ tahun dan kode $2: \geq 3$ tahun. Untuk variabel kepatuhan yaitu : Kode 1 : Pengisian lengkap (bila semua checklist terisi lengkap dan benar), kode 2 : Pengisian tidak lengkap (cheklist ada yang tidak terisi atau terisi plengkap tetapi pengisisan tidak benar). Tahap ketiga adalah memasukkan data menggunakan SPSS 21, Tahap keempat adalah tabulating atau menggelompokkan ke dalam suatu data tertentu berbentuk grafik atau bagan dan pada tahap yang terakhir peneliti mengecek kembali data untuk melihat kemungkinan adanya kesalahan - kesalahan kode atau 
ketidaklengkapan, kemudian dilakukan pembetulan atau koreksi.

\section{Diagram Alir Penelitian}

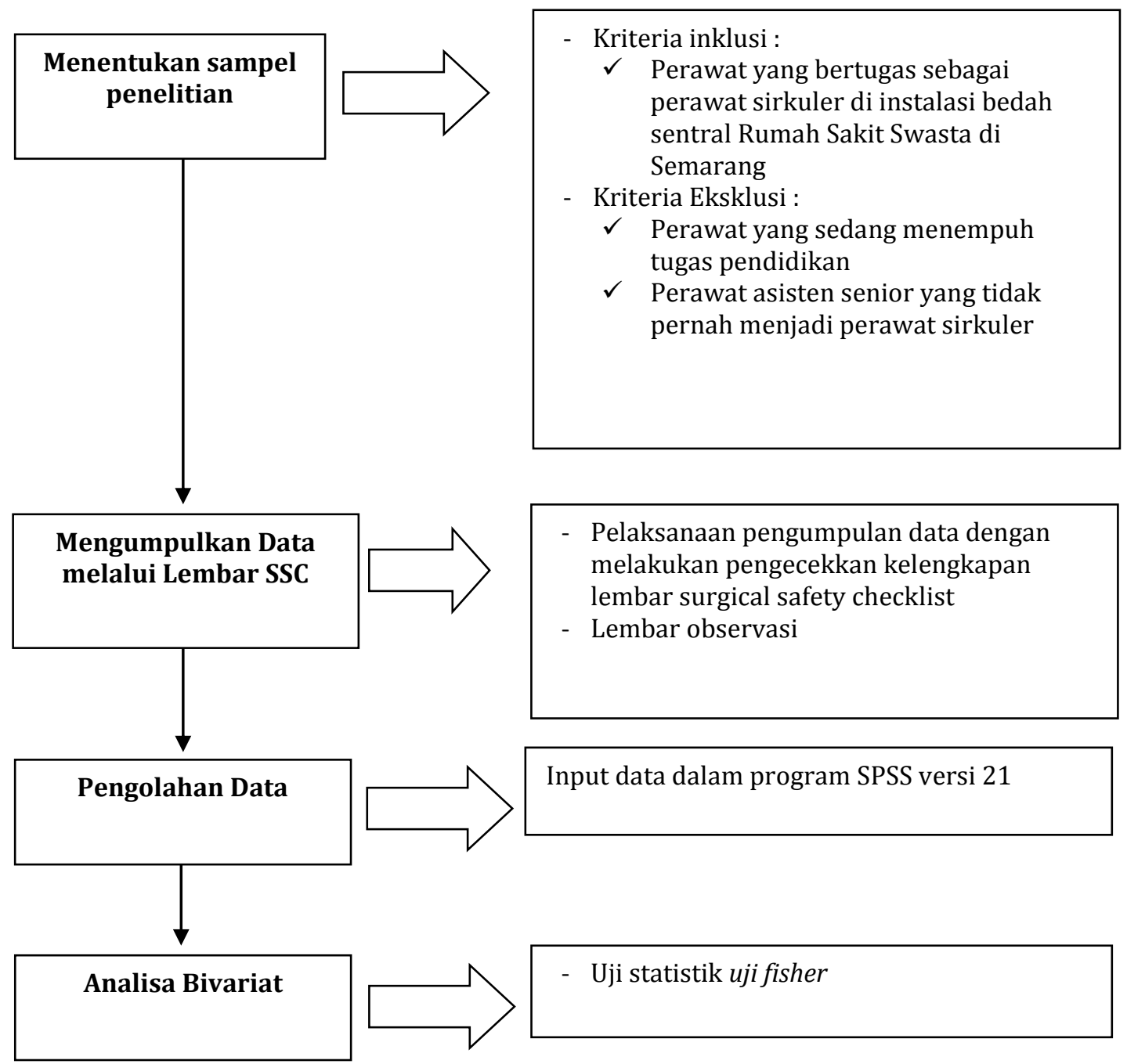

\section{HASIL}

Gambaran umum yang diamati berdasarkan analisis data adalah jenis kelamin, usia, tingkat pendidikan, lama bekerja, pelaksanaan pengisian surgical safety checlist. Didapatkan hasil bahwa dari 23 responden diperoleh, seperti dalam tabel dibawah ini :
Tabel 1 Karakteristik Perawat

\begin{tabular}{lcc}
\hline \multicolumn{1}{c}{ Indikator } & f & \% \\
\hline Jenis Kelamin & & \\
- Laki - laki & 12 & 52,17 \\
- Perempuan & 11 & 47,83 \\
\hline Usia/tahun & & \\
- 20 - 30 & 2 & 8,69 \\
- 31 - 40 & 10 & 43,48 \\
- 41 - 50 & 8 & 34,79 \\
- > 51 & 3 & 13,05 \\
\hline Tingkat Pendidikan & & \\
- D III & 14 & 60,87 \\
- Ners & 9 & 39,13 \\
\hline Lama Bekerja & & \\
- <3 tahun & 8 & 34,8 \\
- $\geq 3$ tahun & 15 & 65,2 \\
\hline Pengisian Surgical Safety & & \\
Checlist & & \\
- Lengkap dan Benar & 5 & 21,7 \\
- Tidak Lengkap & 18 & 78,3 \\
\hline
\end{tabular}


Tabel diatas dari 23 responden diketahui responden terbayak berjenis kelamin laki laki yaitu sebanyak 12 responden $(52,17$ $\%)$, berdasarkan usia terbanyak 31 - 40 tahun yaitu sebanyak 10 responden $(43,48$ $\%)$, dan berdasarkan tingkat pendidikan terbanyak DIII yaitu 14 responden $(60,87$ \%), kemudian dilihat dari lama kerja dari 23 responden lebih dari sama dengan 3 tahun 15 responden $(65,2 \%)$. Dari 23 responden diketahui yang mengisi lembar Surgical Safety Checklist dengan tidak lengkap sebanyak 18 responden (78,3\%).

Tabel 2. Hubungan lama kerja dengan kepatuhan pengisian Surgical Safety Checklist di Indtalasi Bedah Sentral Rumah Sakit Swasta

\begin{tabular}{|c|c|c|c|c|c|}
\hline \multicolumn{6}{|c|}{ Kepatuhan Pengisian Surgical Safety Checklist } \\
\hline \multirow[t]{2}{*}{ Lama Kerja } & \multicolumn{2}{|c|}{$\begin{array}{c}\text { Lengkap } \\
\text { dan benar }\end{array}$} & \multicolumn{2}{|c|}{$\begin{array}{c}\text { Tidak } \\
\text { lengkap }\end{array}$} & $\begin{array}{c}\mathrm{P} \\
\text { Value }\end{array}$ \\
\hline & $\mathrm{n}$ & $\%$ & $\mathrm{n}$ & $\%$ & \multirow{3}{*}{0,586} \\
\hline$<3$ tahun & 2 & $40 \%$ & 6 & 33,3 & \\
\hline$\geq 3$ tahun & 3 & $60 \%$ & 12 & 66,7 & \\
\hline Total & 5 & 100 & 18 & 100 & \\
\hline
\end{tabular}

* Uji Fisher

Hasil penelitian menunjukkan kepatuhan pengisian Surgical Safety Checklist pada kelompok lama kerja < 3 tahun dengan pengisian secara lengkap dan benar sebanyak 2 responden (40\%) dan pengisian tidak lengkap sebanyak 6 responden $(33,6 \%)$ sedangkan untuk kelompok lama kerja $\geq 3$ tahun dengan pengisian secara lengkap dan benar sebanyak 3 responden $(60 \%)$ dan pengisian tidak lengkap sebanyak 12 responden $(66,4 \%)$

Berdasarkan hasil uji fisher didapatkan $p$ value yaitu $0,586(>0,05)$ maka $\mathrm{H}_{0}$ diterima $\mathrm{H}_{\mathrm{a}}$ ditolak, sehingga dapat disimpulkan bahwa tidak ada hubungan lama kerja perawat dengan kepatuhan pengisian Surgical Safety Checklist di Instalasi Bedah Sentral Rumah Sakit Swasta Semarang.

\section{PEMBAHASAN}

Berdasarkan hasil penelitian bahwa 18 dokumen (78,3 \%) tidak lengkap dalam pengisiannya sedangkan 5 dokumen $(21,7$ $\%$ terisi lengkap dan benar. Pendokumentasian yang tidak lengkap atau salah dalam pengisiannya sering terjadi pada fase time out meliputi item konfirmasi pemberian profilaksis antibiotik ada 14 dokumen, estimasi lama operasi dan perkiraan kehilangan darah ada 4 dokumen, sedangkan pada fase sign out meliputi item konfirmasi ulang nama tindakan operasi ada 2 dokumen. Hal ini sejalan dengan hasil penelitian Rosa tentang Pengisian Sign In dalam meningkatkan kepatuhan safe surgery di Rumah Sakit PKU Muhammadiyah Yogyakarta II didapatkan hasil pengisian sign in tidak patuh, karena masih didapatkannya gelang identitas yang belum dipasang pada pasien yang akan dioperasi dan pemberian tanda lokasi operasi yang jarang dilakukan (Rosa, 2015).

Hal yang menyebabkan rendahnya pengisian checklist ini menurut Melekie dan Getahun adalah kurangnya pelatihan sebelumnya $(45,1 \%)$ dan kurangnya kerjasama diantara anggota tim operasi $(21,6 \%)$. Keberhasilan penerapan surgical safety checklist tergantung pada pelatihan staf untuk meningkatkan pengetahuan dan kepatuhan. Tidak dapat diasumsikan bahwa pengenalan checklist secara otomatis akan mengarahkan pada hasil yang lebih baik. Selain itu komunikasi dengan staf sangat penting untuk memperbaiki kepatuhan (Melekie \& Getahun, 2015)

Pendokumentasian yang tidak lengkap atau salah dalam pengisian saat fase time out ini berkaitan dengan kesadaran evaluasi pasca operasi yang kurang dianggap penting. Meskipun telah melewati masa kritis pada keselamatan pasien, namun operator dokter bedah, dokter anastesi dan perawat seharusnya melakukan review masalah utama apa yang harus diperhatikan untuk penyembuhan dan manajemen pasien selanjutnya (Wangoo, Ray, \& Ho, 2016)

Penerapan standar pelayanan keperawatan kamar bedah di rumah sakit dilaksanakan dalam upaya meminimalkan angka Kejadian 
Nyaris Cera (KNC), kejadian tidak diinginkan (KTD) dan sentinel melalui peningkatan mutu pelayanan keperawatan. Strategi dalam penerapan standar pelayanan keperawatan dimulai sebelum (pre) pembedahan, selama (intra) pembedahan dan setelah (post) pembedahan. (Kemenkes RI, n.d.) Penelitian yang dilakukan oleh Siagian tentang Pelaksanaan surgical patient safety terhadap adverse events pascaoperasi bedah digestif di Instalasi Bedah RSUP DR. Sardjito didapatkan hasil pelaksanaan surgical patient safety belum konsisten dilaksanakan dan pelaksanaan surgical patient safety berhubungan dengan terjadinya Adverse Events pascaoperasi Bedah Digestif di Instalasi Bedah Sentral RSUP DR. Sardjito (Siagian, 2011)

Lama bekerja merupakan faktor yang sangat penting dalam keselamatan pasien di rumah sakit. Lama kerja menunjukkan hubungan yang signifikan terhadap asuhan keperawatan yang aman bagi pasien. Hasil penelitian $\mathrm{Ni}$ Luh Putu tentang analisis faktor - faktor yang mempengaruhi perawat didalam melaksanakan patient safety didapatkan hasil ada hubungan antara lama bekerja dengan pelaksanaan patient safety di kamar bedah RS Telogorejo Semarang (Ni Luh Putu, dkk 2013). Lama kerja ini merupakan waktu dimana perawat mulai bekerja sebagai karyawan tetap rumah sakit hingga saat ini. Masa kerja lama (senior) akan mendapatkan pengalaman yang lebih banyak dari pada yang memiliki masa kerja yang pendek. Semakin lama perawat bekerja, semakin banyak kasus spesifik yang ditangani sehingga semakin meningkatkan pengalaman (pemikiran dan tindakan). Penelitian ini berbeda dengan hasil penelitian yang dilakukan oleh peneliti dimana berdasarkan hasil analisis hubungan kedua variable dengan menggunakan uji statistik fisher didapatkan data $p$ value yaitu $0,586(>0,05)$ maka $\mathrm{H}_{\mathrm{o}}$ diterima $\mathrm{H}_{\mathrm{a}}$ ditolak, sehingga dapat disimpulkan bahwa tidak ada hubungan lama kerja perawat dengan kepatuhan pengisian surgical safety checklist di
Instalasi Bedah Sentral Rumah Sakit Swasta Semarang.

Menurut teori yang ada bahwa semakin lama seseorang bekerja maka semakin baik tingkat produktifitas yang dihasilkan. Namun terdapat banyak faktor yang mempengaruhi pelaksanaan pendokumentasian surgical safety checklist. Faktor yang mempengaruhi kepatuhan penerapan surgical safety checklist antara lain belum adanya kebijakan sasaran keselamatan pasien dan penerapan surgical safety checklist, kurang sosialisasi SPO untuk dokter dan perawat, kurangnya pengetahuan tentang surgical safety checklist, kurang kesadaran pentingnya surgical safety checklist, jumlah perawat kamar bedah kurang, merasa pengisian Surgical Safety Checklist sebagai beban kerja tambahan. (Sandrawati J. 2013).

\section{SIMPULAN}

Hasil penelitian ini menunjukkan tidak ada hubungan lama kerja perawat dengan kepatuhan pengisian surgical safety checklist di Instalasi Bedah Sentral Rumah Sakit Swasta Semarang dengan nilai $p$ value yaitu $0,586>0,05$. Hasil penelitian ini diharapkan dapat memberikan tambahan ilmu pengetahuan dalam bidang manajemen keperawatan sehingga menghasilkan penelitian yang lebih baik.

\section{REFERENSI}

Bramantoro, 2017. Pengantar Klasifikasi dan Akreditasi Pelayanan Kesehatan: Penjelasan Praktis ... - Google Buku. (n.d.). Retrieved from https://books.google.co.id/books?id=4UV7D wAAQBAJ\&pg=PA11\&dq=pengertian+rumah+ sakit\&hl=id\&sa=X\&ved=0ahUKEwiSyZaCusrh AhUM7HMBHdlUBNQQ6AEIPDAE\#v=onepag $\mathrm{e} \& \mathrm{q}=$ pengertian rumah sakit\&f=false

D, Madden 2018. Building a Culture of Patient Safety - Report of the Commission on Patient Safety and Quality Assurance | Department of Health. (n.d.). Retrieved from https://health.gov.ie/blog/publications/build ing-a-culture-of-patient-safety-report-of-the- 
commission-on-patient-safety-and-qualityassurance/

Biyang, fanny. 2008. Panduan Nasional Keselamatan Pasien Patient Safety 2008. Retrieved from https://www.academia.edu/9166399/Pandu an_Nasional_Keselamatan_Pasien_Patient_Safe ty_2008

Diah Pratiwi Renoningsih. 2016. 106-207-1SM.docx. Retrieved from https://www.scribd.com/document/4038073 86/106-207-1-SM-docx

Karlina, S. 2018. Evaluasi Kepatuhan Tim Bedah Dalam Penerapansurgical Safety Checklist Who Pada Operasi Bedah Mayor Di Instalasi Bedah Sentral PKU MUHAMMADIYAH BANTUL. Retrieved from http://repository.umy.ac.id/handle/1234567 $89 / 22824$

Trisna, E. 2016. Hubungan Persepsi Tim Bedah dengan Kepatuhan Penerapan Surgical Patient Safety pada Pasien Operasi Bedah Rumah Sakit Umum Daerah Mayjend HM. Ryacudu. Jurnal Kesehatan, 7(2), 341. https://doi.org/10.26630/jk.v7i2.209

Apriana, R., astuti, W., \& Dedy, Y. 2018. Hubungan Beban Kerja Dengan Kepatuhan Pengisian Surgical Patient Safety Checklist Pada Perawat Di Ruang Instalasi Bedah Sentral Rumah Sakit St. Elisabeth Semarang. Jurnal Ners Widya Husada Semarang, 3(1). https://doi.org/10.33666/JNERS.V3I1.160

Universitas Muhammadiyah Yogyakarta, A. F., \& Rosa, E. M. 2015. JMMR: jurnal medicoeticolegal dan manajemen rumah Sakit. In JMMR (Jurnal Medicoeticolegal dan Manajemen Rumah Sakit) (Vol. 4). Retrieved from

http://journal.umy.ac.id/index.php/mrs/artic le/view/687

Melekie, T. B., \& Getahun, G. M. 2015. Compliance with Surgical Safety Checklist completion in the operating room of University of Gondar Hospital, Northwest Ethiopia. BMC Research Notes, 8(1), 361. https://doi.org/10.1186/s13104-0151338-y

Wangoo, L., Ray, R. A., \& Ho, Y.-H. 2016. Compliance and Surgical Team Perceptions of WHO Surgical Safety Checklist; Systematic Review. International Surgery, 101(1-2), 35-49. https://doi.org/10.9738/INTSURG-D-1500105.1

Kemenkes RI, Ta. 2011. (N.D.). Isi Standar Pelayanan Keperawatan Kamar Bedah.Pdf. Retrieved From

Https://Www.Scribd.Com/Doc/276590271/I si-Standar-Pelayanan-Keperawatan-KamarBedah-Pdf

Siagian, E. 2011. Pelaksanaan Surgical Patient Safety Terhadap adverse Events Pascaoperasi Bedah Digestifdi Instalasi Bedah Rsup Dr. Sardjito Yogyakarta. Retrieved fromhttp://etd.repository.ugm.ac.id/index.ph p?mod=penelitian_detail\&sub=PenelitianDeta il\&act=view\&typ=html\&buku_id=52033

Ni Luh Putu, dkk 2013. Analisis Faktor - Faktor Yang Mempengaruhi Perawat Didalam Melaksanakan Patient Safety Didapatkan Hasil Ada Hubungan Antara Lama Bekerja Dengan Pelaksanaan Patient Safety Di Kamar Bedah RS Telogorejo Semarang

https://s3.amazonaws.com/academia.edu.document s/34012675/niluh_poster.pdf?AWSAccessKey Id=AKIAIWOWYYGZ2Y53UL3A\&Expires=155 5102442\&Signature=L7e1V6It\%2B9\%2BCLp G2Ljo3teYsdiQ\%3D\&response-contentdisposition=inline $\% 3 \mathrm{~B} \% 20$ filename $\% 3$ Dpost er_presentation.pdf

Sandrawati J. 2013. Rekomendasi untuk menigkatkan kepatuhan penerapan surgical safety checklist di kamar bedah. Buletin penelitaan Sistem Kesehatan- volume 17, No. 1 